REVISTA DE LA CEPAL 83 *AGOSTO 2004

\section{El empleo rural no agrícola y la diversidad rural en América Latina}

el decenio de 1990 el empleo rural no agrícola (ERNA) y los factores que lo determinan fueron despertando un interés cada vez mayor entre los especialistas en desarrollo rural. Poco a poco, en el discurso político y algunos programas de fomento se fueron incorporando consideraciones sobre este tema. La localización es uno de los aspectos mencionados en muchos estudios como un elemento que influye en las características del ERNA, entre las cuales están la magnitud, el tipo, el ingreso generado y los miembros del hogar que participan. El presente artículo recoge esas menciones y postula que la localización y las diversas "distancias" que la acompañan constituyen un elemento central del ERNA. 


\section{I}

\section{Introducción}

Para delinear política es importante saber si todas las zonas rurales pueden tener economías diversificadas, y si los campesinos pobres son capaces de optimizar las oportunidades que les ofrezca el empleo rural no agrícola (ERNA) o si para hacerlo necesitan la ayuda de políticas especiales. La información de que se dispone revela que las modalidades de participación y las posibilidades de aprovechar las oportunidades difieren marcadamente entre los grupos de población, según el género, la edad $\mathrm{y}$, sobre todo, el patrimonio personal o del hogar, la localización de su residencia y el acceso a bienes públicos y privados. En este artículo se aborda, entre otros, un tema poco estudiado: la relación de la localización en el territorio - $-\mathrm{y}$, por lo tanto, las "distancias" - con el ERNA.

Desde el decenio de 1990 en América Latina se ha estado prestando creciente atención al ERNA. Diversos estudios han examinado la forma en que se relacionan con él los distintos activos (públicos y privados) en cada grupo de ingresos y, a la vez, la forma en que las distintas ocupaciones no agrícolas influyen

\section{II}

\section{Definiciones}

El empleo no agrícola de los residentes en zonas rurales puede abordarse de distintas maneras, entre las cuales destacaremos tres. La primera de ellas generalmente gira en torno a estudios de casos sobre una de las ocupaciones de los miembros del hogar, tomando

\footnotetext{
$\square$ Una versión anterior del presente artículo fue presentada en el simposio "The rural non-farm economy in the developing world and transition economies: an answer to rural poverty?", en el marco de la 77a conferencia anual de la Agricultural Economics Society del Reino Unido (Seale-Hayne, Newton Abbott, Devon, 11 a 14 de abril de 2003). Una versión abreviada se presentó con el título de "Rural non-farm employment: the importance of distances" en la sesión dedicada a transformaciones sociales del seminario internacional "El mundo rural: transformaciones y perspectivas a la luz de la nueva ruralidad" (Bogotá, 15 a 17 de octubre de 2003). La autora agradece las útiles observaciones de Steve Wiggins, del Overseas Development Institute, y las de un juez anónimo que comentó ese artículo.
}

en los ingresos mismos. Varios de esos estudios fueron publicados en una edición especial de World Development (2001) dedicada al empleo y los ingresos rurales no agrícolas, y recientemente aparecieron traducidos al español (BID/FAO/CEPAL/RIMISP, 2004). Aquí recurriremos ampliamente a esos trabajos.

El presente artículo consta de siete secciones. La sección II siguiente explica algunas de las definiciones utilizadas en América Latina y las que se emplearán en el resto del texto. La sección III reseña las causas del crecimiento del ERNA. La sección IV muestra la magnitud del ERNA en América Latina. La sección $\mathrm{V}$ trata del ERNA y los activos privados (tierra, educación, características de los miembros del hogar) y públicos (caminos, electrificación), pero también de la localización y el dinamismo de la agricultura local. La sección VI examina el ERNA y las "distancias". Y, por último, la sección VII contiene algunas conclusiones en materia de políticas y menciona algunos temas que merecen mayor estudio. el hogar como unidad de análisis. El énfasis no recae necesariamente en la actividad principal de la familia ni en la de sus miembros, sino en la actividad que el autor desea examinar con más detalle. ${ }^{1}$ La segunda se centra en la principal actividad o fuente de ingresos del hogar, la que suele obtenerse de las respuestas a las encuestas de hogares, entre las cuales por lo general son determinantes las respuestas del jefe de hogar. La tercera considera la actividad principal de cada persona y tiene como fuentes de información primordiales las encuestas de hogares o los censos de población. El

\footnotetext{
${ }^{1}$ En el Tercer Simposio Latinoamericano sobre investigación y difusión de sistemas agrícolas, que trató de nuevos enfoques para la superación de la pobreza rural y para el desarrollo de las capacidades locales (Lima, agosto de 1998), se dieron a conocer varios ejemplos de esta clase de estudios (sobre la fabricación de sombreros de paja en Perú o la confección de "bluyines" en Ecuador).
} 
análisis que sigue se hará por esta tercera vía y considerará el empleo principal en actividades no agrícolas de residentes en zonas rurales.

Para describir dicho empleo se acuñó en español la expresión "empleo rural no agrícola" (ERNA). El ERNA no incluye las actividades agrícolas realizadas "fuera de la granja" que, según el autor de que se trate, forman o no parte del concepto utilizado en inglés: rural non-farm employment (RNFE). Para simplificar, el presente artículo utilizará la sigla ERNA, como lo han hecho muchos autores y traductores, ciñéndose a la definición de Reardon, Berdegué y Escobar (2001, p. 396), quienes señalan que al hablar de ERNA se refieren al empleo de los miembros de los hogares rurales en el sector no agrícola; que "no agrícola" significa cualquier actividad externa a la agricultura, es decir, en la manufactura o los servicios; que se atienen a las definiciones estándares de las cuentas nacionales, según las cuales la agricultura produce bienes agroalimentarios no procesados utilizando recursos naturales (tierra, ríos/lagos/ océanos, aire) como uno de los factores de producción, y que el proceso puede ser "de cultivo" (siembras, acuicultura, crianza de ganado, silvicultura) o "de recolección" (caza, pesca, silvicultura).

Sin embargo, tanto la sigla en español como la sigla en inglés dan la impresión errónea de que la actividad considerada tiene lugar en una zona rural. Esto ha confundido tanto a los analistas como a quienes formulan políticas y ha alentado cierto entusiasmo por un "renacimiento rural" que, al menos en parte, obedece a una percepción errada de la realidad. En verdad, a lo que se refieren ambas es al empleo de quien reside en una zona definida como rural por el censo de su país y que lleva a cabo una labor no agrícola, sin que se indique el lugar en que realiza dicha labor.
Algo que debe tenerse en cuenta al analizar el ERNA en América Latina es el tema de las definiciones del término "rural". En la región, los censos de población y, por ende, las encuestas de hogares, utilizan cinco definiciones amplias del término que se basan respectivamente en la población máxima de la localidad (alrededor de 2.000 personas por localidad en la mayoría de los países); en el número de viviendas contiguas (Perú); en definiciones legales (Brasil, Ecuador, Guatemala, Uruguay); en el hecho de encontrarse fuera de la denominada "cabecera municipal" (Colombia, República Dominicana, El Salvador, Paraguay) y en "características no rurales" (Costa Rica y Haití). Además, casi ningún país utiliza exactamente la misma definición que otro y varios la han modificado a lo largo de los años.

La mayoría de las zonas rurales de la región se caracteriza por una baja densidad poblacional y por grandes distancias físicas y de otra naturaleza entre asentamientos. De hecho, en América Latina la densidad media de la población es de 21 habitantes por $\mathrm{km}^{2}$ (fluctúa entre 257 en El Salvador y seis en Bolivia), lo que equivale a menos de la quinta parte del promedio de la Unión Europea (15 países), a un poco menos que el promedio del África subsahariana y a bastante menos que el de otras regiones en desarrollo. En cuanto a la población dispersa, ${ }^{2}$ América Latina en su conjunto tiene 6,7 habitantes por $\mathrm{km}^{2}$, mientras que en países como Argentina, Bolivia, Chile, Uruguay y Venezuela la cifra es inferior a la mitad y resulta bajísima según los estándares europeos (Persson y Ceccato, 2001). La importancia que reviste para la estructura del ERNA esta baja densidad de población y las "distancias" asociadas a ella es uno de los temas que trataremos de subrayar — si no demostrar- en el presente artículo.

\section{III}

\section{Causas del incremento del empleo rural no agrícola}

Según datos tomados de censos de población latinoamericanos, el ERNA se habría elevado de alrededor de $17 \%$ de la población económicamente activa (PEA) rural en el decenio de 1970 a $24 \%$ de la PEA rural en el decenio de 1980; esto es, su aumento anual habría sido de 4,3\%. La PEA agrícola, en tanto, sólo se elevó en

\footnotetext{
${ }^{2}$ Calculada dividiendo la población de las localidades con menos de 2.000 habitantes por el $90 \%$ de la superficie total del país. El cálculo es más bien moderado, puesto que de acuerdo con estimaciones del Centro de las Naciones Unidas para los Asentamientos Humanos (CNUAH, 1996, p. 418), en la mayoría de los países las zonas urbanas no sobrepasan el $1 \%$ del territorio nacional.
} 
0,03\% al año. En rigor, el empleo agrícola bajó en casi la mitad de los países latinoamericanos, mientras que el ERNA aumentó en todos ellos. ${ }^{3}$ Como se verá más adelante, en la década de 1990 el ERNA volvió a aumentar apreciablemente.

En las zonas rurales de América Latina la pobreza se ha mantenido en niveles más o menos estables (en términos porcentuales) durante varios decenios. Puede sostenerse, por lo tanto, que el incremento del ERNA no se debió a un aumento de la pobreza, pese a que hay evidencias de que buena parte de las microempresas rurales se crean para paliar la pobreza más extrema.

La población rural y el empleo agrícola también se han mantenido más o menos estables en los últimos decenios. Sin embargo, entre las personas dedicadas principalmente a actividades agrícolas se observan cambios de lugar de residencia, con una creciente tendencia a vivir en zonas urbanas; esto sucede entre migrantes recientes que encuentran menos barreras al empleo como obreros agrícolas ocasionales que en el mercado de trabajo de las ciudades (Hataya, 1992), y también entre agricultores relativamente más prósperos que siguen trabajando en su actividad agrícola pero se trasladan a vivir en zonas más urbanas (Berdegué, Ramírez y otros, 2001). A primera vista, esto no explica el crecimiento del ERNA.

En los últimos tres decenios, la agricultura creció a una tasa media anual relativamente vigorosa de 2 a 3\%. Aunque no sé de cálculos similares respecto de la economía rural, es probable que ésta haya crecido al menos en proporciones parecidas. Por lo tanto, el incremento del ERNA podría ser una reacción "normal" ante el crecimiento y también ante la mayor demanda de servicios de una agricultura en vías de modernización. Sigue siendo una incógnita por qué han de prestar estos servicios los residentes rurales mientras los agricultores se trasladan a vivir en zonas urbanas.

También es posible que haya varones jóvenes y de edad mediana que resuelven seguir viviendo en zonas rurales (por motivos relacionados con la vivienda, su gusto por la vida familiar, su preferencia por el estilo de vida rural, etc.) pero que no quieren dedicarse a la agricultura o no tienen acceso a tierras de cultivo (Dirven, 2002). En consecuencia, postulan a empleos rurales no agrícolas, o "crean" empleos de esta

\footnotetext{
${ }^{3}$ Reardon, Berdegué y Escobar (2001), a partir de cifras de Klein
} (1992). índole, o bien, si la distancia lo permite, se trasladan diariamente a trabajar en una zona urbana.

Otra causa del incremento del ERNA podría ser la incorporación a la fuerza de trabajo de mujeres rurales (en su mayoría jóvenes), lo que las pone ante las mismas opciones que confrontan los varones jóvenes: migrar, permanecer en zonas rurales pero fuera de la actividad agrícola, o viajar diariamente hasta su lugar de trabajo.

Un hallazgo reciente - que hay que investigar más a fondo, pero que probablemente guarda estrecha relación con lo señalado en los dos párrafos anteriores y con la localización del ERNA, a la cual volveremos luego- es que los más jóvenes parecen concentrarse i) en torno a zonas más dinámicas, próximas a pequeños pueblos o villorrios rurales que han dado muestras de progreso económico o han recibido recientes inversiones del gobierno, a menudo relacionadas con la mitigación de la pobreza o con políticas de descentralización; o ii) en zonas situadas cerca de caminos pavimentados que conducen a esos centros más dinámicos. ${ }^{4}$

Esto nos lleva a destacar la importancia que tuvieron para el crecimiento del ERNA las políticas de descentralización y desarrollo rural aplicadas en la mayoría de los países latinoamericanos durante el decenio de 1990. Gracias a esas políticas se crearon nuevos empleos en municipios y gobiernos regionales, así como en los servicios de salud, educación, crédito, asistencia técnica, infraestructura y otros. La verdad es que hasta en municipios muy poco dinámicos de zonas con agudos procesos de desertificación y claros patrones de emigración neta se observa la llegada de nuevos migrantes de todas las edades y diversos perfiles de empleo, aunque predominan entre ellos los funcionarios públicos y los consultores, técnicos y voluntarios de organizaciones no gubernamentales (Morales, 2003).

Otro factor que puede explicar el incremento del ERNA es la mayor demanda originada por el turismo; por residentes urbanos adinerados que pasan fines de semana y vacaciones en segundas viviendas, o por residentes en zonas periurbanas - pobres o relativamente prósperos - que quieren vivir a distancia y tiem-

\footnotetext{
${ }^{4}$ Estas aseveraciones se basan en una interpretación visual de los mapas preparados por Pablo Ávalos como parte de su pasantía en la Unidad de Desarrollo Agrícola de la CEPAL y de la preparación de su tesis como geógrafo de la Universidad de Chile. Ávalos elaboró una serie de mapas de la VI, VIII y IX regiones de Chile y comparó los datos de la estructura por edades y género de los censos de población de 1992 y 2002 a nivel de distritos censales, para lo cual utilizó el programa de recuperación de datos para áreas pequeñas por microcomputador (Redatam), desarrollado por CEPAL/CELADE.
} 
po de traslado "razonables" de las zonas urbanas, que disfrutan la vida en el campo o que desean invertir menos en vivienda. ${ }^{5}$

Según de Janvry y Sadoulet (1993), ${ }^{6}$ la distribución extremadamente inequitativa de los activos en América Latina, peor que en otras regiones, dificulta la creación de vinculaciones locales. En realidad, debido a la marcada asimetría de la distribución del ingreso y de la tierra (con coeficientes de Gini en torno a 0.60 y a 0.80 , respectivamente), la mayor parte de los beneficios por concepto de ingresos que produce el crecimiento agrícola va a un número reducido de terratenientes. Ellos son en su mayoría propietarios ausentes, de manera que la mayor parte de esos ingresos no acrecienta la demanda local. Sin embargo, esto no impide que el sector agrícola moderno, que en
América Latina es relativamente amplio, utilice más insumos y servicios que la agricultura de otras regiones en desarrollo y, por lo tanto, genere vinculaciones relativamente vigorosas con el resto de la economía, aunque no tanto en el plano local (de Janvry y Sadoulet, 2002, p. 18). Estimaciones recientes realizadas en 2003 por el Instituto Interamericano de Cooperación para la Agricultura (IICA) en varios países de la región muestran multiplicadores agrícolas de alrededor de 3 , que en todo caso son bastante modestos si se les compara con los de países desarrollados (el mismo estudio registró un multiplicador de 11 para los Estados Unidos). Todavía no está claro cuánto de esto se traduce en empleo rural no agrícola, y en qué condiciones. Esto es algo que habría que estudiar más a fondo.

\section{IV}

\section{El empleo rural no agrícola en cifras: panorama a fines del decenio de 1990}

Mediante la ampliación de las cifras que entregaron las encuestas de hogares realizadas en 1999 calculamos el ERNA de once países latinoamericanos, ${ }^{7}$ que en conjunto representan alrededor de $72 \%$ de la población económicamente activa de América Latina ${ }^{8}$ (esto es, la población empleada y desempleada). El ERNA resultante fue de $39 \%$ de la población rural ocupada (cuadros 1 y 2). Esto marca un incremento apreciable respecto de estimaciones de comienzos y mediados del decenio de 1990, que fluctuaron en torno al 30-35\%. ${ }^{9}$ Para obtener el cuadro 1 se utilizaron las respuestas a una pregunta de las encuestas de hogares: ¿cuál fue su actividad principal la semana pasada? ${ }^{10} \mathrm{La}$ cifra total que se

\footnotetext{
${ }^{5}$ Véase, entre otros, Graziano da Silva y del Grossi (2001).

${ }^{6}$ Mencionados por Lanjouw (2001).

${ }^{7}$ Países que cuentan con encuestas de hogares de cobertura nacional y para los cuales la CEPAL disponía de microdatos. Ellos son Bolivia Brasil, Chile, Colombia, Costa Rica, El Salvador, Honduras, México, Nicaragua, Panamá y Paraguay.

${ }^{8}$ Además de los países comprendidos de norte a sur entre México y Chile/Argentina, la expresión "América Latina" incluye Cuba, Haití y la República Dominicana, no así los países angloparlantes del Caribe, Belice y Guyana.

${ }^{9}$ Véase, entre otros, Dirven (2000) y Reardon, Berdegué y Escobar (2001).

${ }^{10}$ En algunos países, el período de referencia es el último mes. Las encuestas son extremadamente sensibles al momento en que se rea-
}

obtuvo, en especial la que se refiere a las mujeres, excede considerablemente las proyecciones efectuadas por CEPAL/CELADE (1999) ${ }^{11}$ de la población económicamente activa para el año 2000 (que incluye el 2 a 3\% de población rural desempleada). Esto podría tener tres explicaciones: i) una de índole metodológica: las cifras del CELADE se basan en censos de población, que no captan tan bien el empleo — en especial de las mujerescomo las encuestas de hogares; ii) se incorporó a la fuerza de trabajo un número de mujeres superior al previsto, y iii) se está produciendo un fenómeno similar al de la "década perdida" de 1980, esto es, que las migraciones del campo a la ciudad han disminuido como resultado de una nueva "media década perdida" (1998-2002), fenómeno que fue captado por las encuestas de hogares realizadas en 1999.

La población ocupada total de los 11 países examinados es cercana a los 140 millones de personas, de

\footnotetext{
lizan y al período abarcado. En Brasil, por ejemplo, 14,6 millones de personas respondieron que en 1997 su principal actividad había sido la agricultura. Cuando el período de referencia fue la última semana de septiembre de ese mismo año, sólo 13,4 millones dieron esa respuesta (Graziano da Silva y del Grossi, 2001).

11 Actual División de Población de la CEPAL, antes Centro Latinoamericano y Caribeño de Demografía. (CELADE).
} 


Total 140141814
$100,0 \%=\begin{gathered}\text { Urbana: } 97601576 \\ 69,6 \%\end{gathered}$
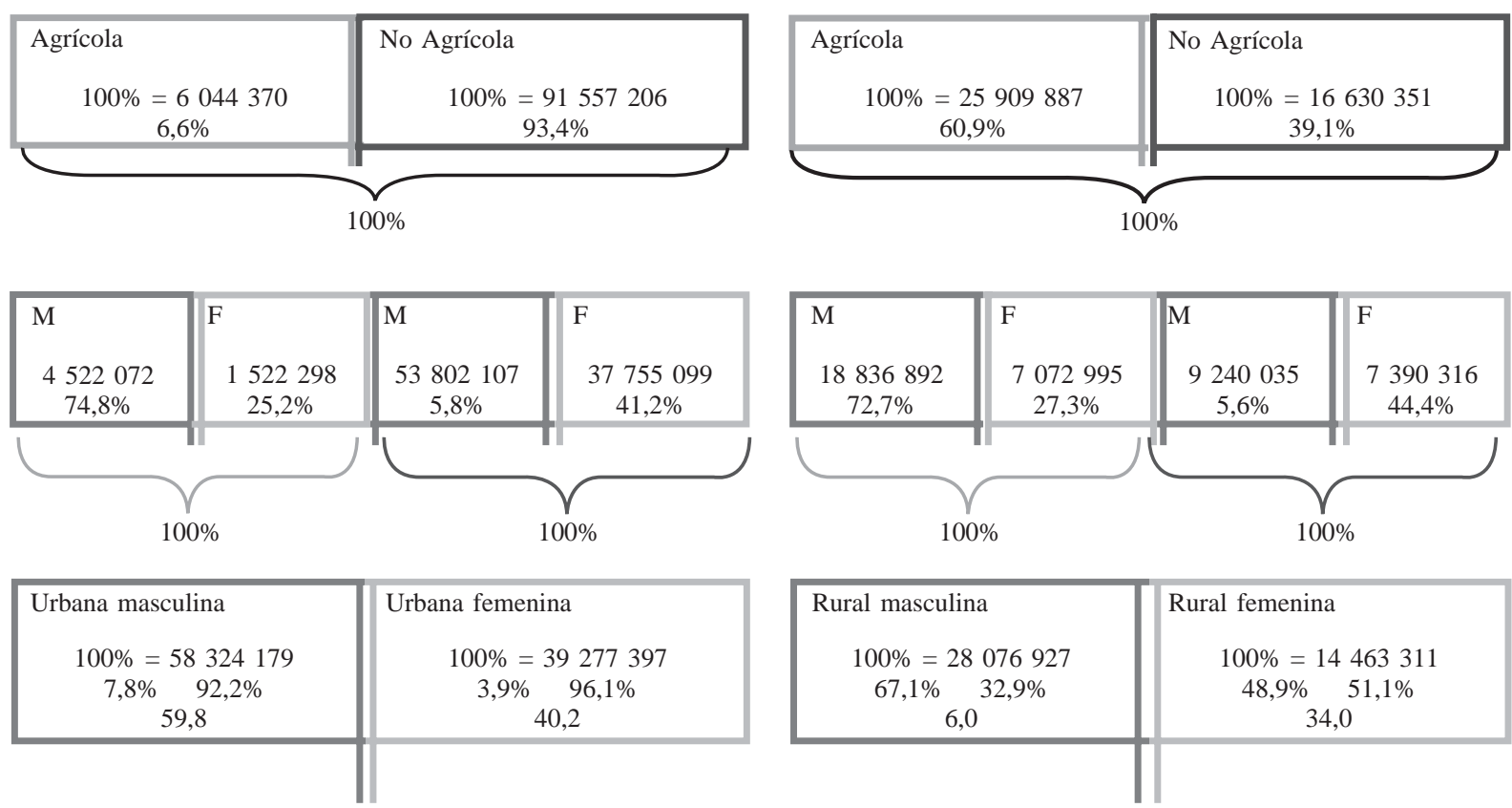

Fuente: Elaboración propia, a partir de extrapolaciones para 1999 de encuestas de hogares en Chile, Colombia, Costa Rica, El Salvador, Honduras, México, Nicaragua, Panamá y Paraguay realizadas por la Unidad Mujer y Desarrollo, de la CEPAL.

CUADRO 2
América Latina (11 países): Población urbana ocupada en actividades agrícolas, y población rural ocupada en actividades agrícolas y en empleo rural no agrícola (ERNA)
(Número de personas y porcentajes)

\begin{tabular}{|c|c|c|c|c|c|c|c|c|}
\hline & \multicolumn{2}{|c|}{ Urbana } & \multicolumn{4}{|c|}{ Rural } & \multicolumn{2}{|c|}{ Total rural } \\
\hline & $\begin{array}{l}\text { En activ. } \\
\text { agrícolas }\end{array}$ & $\begin{array}{c}\text { Mujeres } \\
(\%)\end{array}$ & $\begin{array}{l}\text { En activ. } \\
\text { agrícolas }\end{array}$ & $\begin{array}{c}\text { Mujeres } \\
(\%)\end{array}$ & ERNA & $\begin{array}{c}\text { Mujeres } \\
(\%)\end{array}$ & & $\begin{array}{c}\text { Mujeres } \\
(\%)\end{array}$ \\
\hline Bolivia & 75066 & 25,8 & 1192603 & 45,9 & 202024 & 45,5 & 1394627 & 45,9 \\
\hline Brasil & 4476541 & 27,8 & 11689984 & 36,7 & 4239238 & 44,3 & 15929222 & 38,7 \\
\hline Chile & 279070 & 19,6 & 456893 & 10,9 & 235594 & 39,3 & 692487 & 20,5 \\
\hline Colombia & 298067 & 12,3 & 3183960 & 11,5 & 2462521 & 49,1 & 5646482 & 27,9 \\
\hline Costa Rica & 30791 & 8,8 & 220977 & 7,7 & 425662 & 36,3 & 646639 & 26,5 \\
\hline El Salvador & 72870 & 9,1 & 399037 & 7,5 & 386139 & 48,1 & 785176 & 27,5 \\
\hline Honduras & 84390 & 10,1 & 647926 & 6,0 & 448022 & 59,7 & 1095949 & 27,9 \\
\hline México & 536329 & 23,3 & 6974498 & 22,5 & 7528597 & 42,3 & 14503095 & 32,8 \\
\hline Nicaragua & 95120 & 13,5 & 445780 & 9,8 & 229823 & 49,8 & 675603 & 23,4 \\
\hline Panamá & 47465 & 4,0 & 121666 & 3,6 & 127608 & 38,7 & 249274 & 21,6 \\
\hline Paraguay & 48660 & 17,4 & 576563 & 20,5 & 345121 & 45,7 & 921684 & 29,9 \\
\hline Total & 6044370 & 25,2 & 25909887 & 27,3 & 16630351 & 44,4 & 42540238 & 34,0 \\
\hline
\end{tabular}

Fuente: Elaboración propia, a partir de extrapolaciones para 1999 de encuestas de hogares realizadas por la Unidad Mujer y Desarrollo, de la CEPAL. 


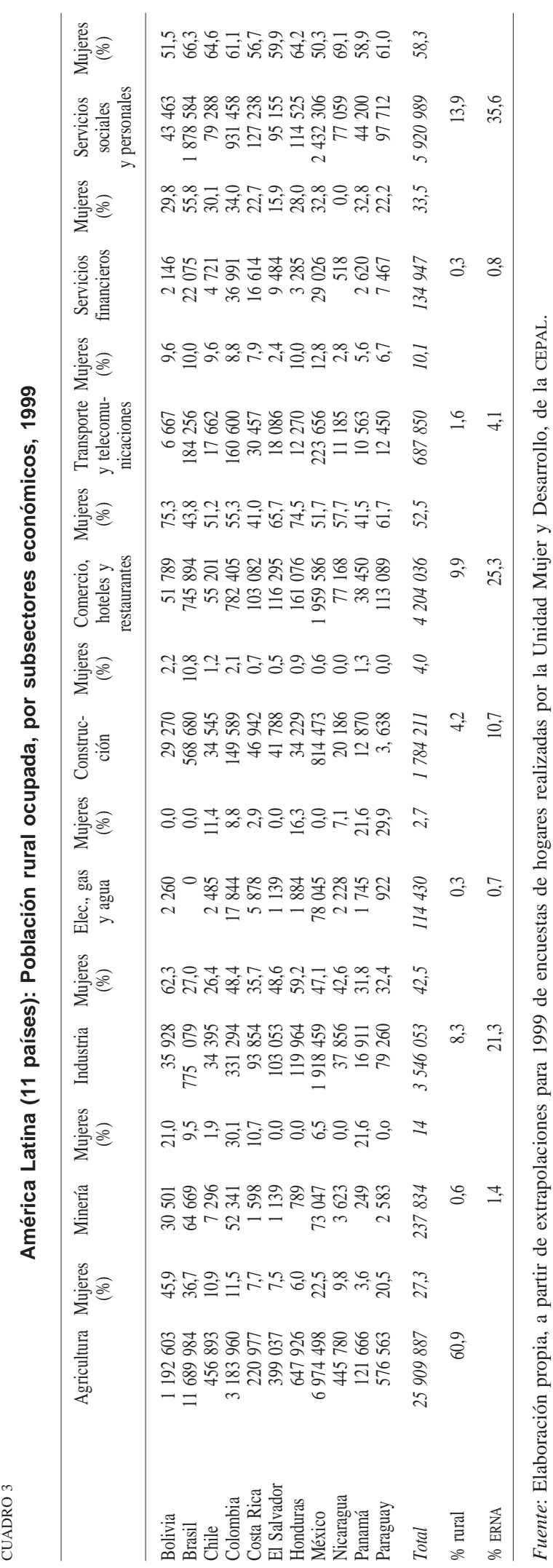

las cuales $30 \%$ vive en zonas rurales. De los residentes urbanos ocupados, cerca de $6,6 \%$ trabaja principalmente en la agricultura (en especial los mayores de 45 años) y de los residentes rurales ocupados alrededor del $39 \%$ realiza actividades no agrícolas (en especial los menores de 45 años, y sobre todo aquellos entre 30 y 44 años).

La participación de las mujeres ocupadas rurales y urbanas en actividades no agrícolas es superior a su participación en actividades agrícolas. ${ }^{12}$ Las mujeres representan el 44,4\% del ERNA y el $41,2 \%$ de los ocupados urbanos que trabajan en actividades no agrícolas. En el empleo agrícola rural, las mujeres representan el 27,3\%, y en el empleo agrícola urbano, el 25,2\% de los ocupados urbanos que se dedican a actividades agrícolas.

En estudios anteriores, Dirven (2002 y 2000) mostró que la incidencia de mayores de 60 años (hombres y mujeres) es claramente más alta en la PEA rural $(8,3 \%)$ que en la urbana $(4,6 \%)$. Esto se explica por el peso de la PEA agrícola en la PEA rural y por el hecho de que $10 \%$ de la primera tiene más de 60 años. Por su parte, la participación del grupo etario de 30 a 44 años en la PEA agrícola es inferior, debido a la migración. En cambio, el grupo etario de 15 a 29 años tiene representación similar en las zonas rurales y urbanas, ya que aun cuando en las primeras la actividad laboral se inicia a una edad más temprana, en este grupo hay especial prevalencia de la migración.

La PEA femenina dedicada a actividades rurales no agrícolas muestra claramente una importante participación de las jóvenes: casi la mitad tiene entre 15 y 29 años. Del total de mujeres rurales ocupadas, un elevado $51 \%$ se desempeña en el ERNA, mientras que entre los hombres la proporción es de $33 \%$.

Desde el punto de vista del empleo, los sectores más importantes son i) los servicios sociales, comunales y personales; ii) el comercio, los hoteles y los restaurantes, y iii) la manufactura, que representan respectivamente $36 \%, 25 \%$ y $21 \%$ del ERNA total. Curiosamente, estos tres sectores también se caracterizan por una marcada participación de mujeres: $51 \%, 53 \%$ y $43 \%$, respectivamente (cuadro 3 ).

\footnotetext{
${ }^{12}$ Esto se debe en parte a información incompleta, pese a que la OIT ha realizado grandes esfuerzos por fomentar el uso de preguntas concretas sobre el trabajo agrícola de la mujer. Gracias a esos esfuerzos, a mediados del decenio de 1990 las cifras de la FAO para la PEA agrícola en América Latina aumentaron de 40 a 44 millones de personas entre la base de datos anterior a 1994 y la que se inicia en 1990.
} 
Reardon, Berdegué y Escobar (2001) encontraron que en América Latina el $46 \%$ de los ingresos que perciben los residentes rurales proviene de actividades no agrícolas; este porcentaje supera el del ERNA como actividad principal. En promedio, entonces, la productividad del ERNA parece ser mayor que la de las actividades agrícolas. Cabe señalar, sin embargo, que el ingreso no agrícola total suele calcularse incluyendo las transferencias públicas y privadas. Además, parte del ERNA corresponde a actividades secundarias, mientras que las cifras relativas a los ocupados se refieren sólo a su actividad principal. Ambas cosas llevan a sobreestimar la productividad media del ERNA. En qué medida lo hacen es lo que ilustran por ejemplo Berdegué, Ramírez y otros (2001) respecto de Chile. Estos autores comprobaron que las transferencias constituían $35 \%$ del ingreso total en un municipio rural pobre (Portezuelo), y que representaban $22 \%$ del ingreso de las personas sin tierras y $12 \%$ del de aquellas con tierras en un municipio rural más rico (Molina).

Hay que tener en cuenta, sin embargo, que en el ERNA es posible distinguir dos clases de actividades: por un lado, las de baja productividad que son un "refugio contra la pobreza", brindan remuneraciones bajas, no tienen grandes barreras de entrada o salida, y son generadas sobre todo por la oferta; y por otro lado, las actividades dinámicas, de mayor productividad, ${ }^{13}$ generadas principalmente por la demanda, pero que imponen barreras relativamente altas a la entrada en términos de capital financiero y humano. En la mayoría de los casos, la participación relativa de los ingresos provenientes del ERNA en el ingreso total, en relación con los activos de los hogares (en especial la tierra), forma una curva en $\mathrm{U}$, mientras que el total de ingresos procedentes del ERNA generalmente aumenta con los distintos activos (tierra, educación, capital, acceso a caminos y otra infraestructura, y proximidad a los mercados o más bien a concentraciones de población).

En América Latina, los mercados de trabajo rurales distan mucho de ser perfectos y a menudo los salarios de cuenta difieren de los salarios de mercado. En ellos influye la productividad marginal de la mano de obra, pero también el precio de los bienes de consumo, los costos de transacción, el tiempo disponible, los ingresos no laborales, la dotación de activos públicos y privados, y la indivisibilidad de algunas decisiones de producción o de consumo. En consecuencia, las decisiones relativas a la asignación del trabajo a asalariados o a trabajadores por cuenta propia en la agricultura o en el ERNA dependen de todos estos aspectos.

En seguida, y utilizando principalmente información contenida en World Development (2001), trataremos de avanzar desde una visión "plana e indefinida" de "lo rural" a una descripción mucho más compleja, que hace hincapié en las "distancias".

\section{V}

\section{Activos y empleo rural no agrícola}

\section{Activos privados}

\section{a) Tierra}

La información disponible acerca de la relación entre los activos territoriales de los hogares y el ERNA no es unívoca. Pese a que en muchos casos se da la

\footnotetext{
${ }^{13}$ La mayoría de los autores distinguen entre el ERNA de "alta" productividad y el de "baja" productividad. Aquí hemos preferido hablar en el primer caso de ERNA de productividad "mayor", para evitar confusiones con los empleos de alta productividad real y elevados ingresos a los que, por desgracia, en América Latina acceden muy pocos residentes rurales. En realidad, como lo indica Wiggins (2003) para el caso de México, en vez de dos categorías estrictas de ingresos por concepto de ERNA, hay un continuo que va de ingresos muy bajos a ingresos relativamente altos.
}

curva en U antes mencionada, Reardon, Berdegué y Escobar (2001) concluyen más bien que la participación de los ingresos provenientes del ERNA en el ingreso total del hogar disminuye a medida que aumenta la cantidad de tierra que éste posee, pues los poseedores de más tierras tienen menos incentivo para depender del ERNA. Por otra parte, la evidencia disponible indica que los ingresos del ERNA se elevan a la par con el ingreso de los hogares.

Según la reseña general incluida en la edición especial de World Development (2001), tanto en Perú (Escobal, 2001) como en México (Yúnez-Naude y Taylor, 2001) el hecho de ser propietario de activos fijos agrícolas aumenta la participación del ingreso agrícola en el ingreso total del hogar, y disminuye la 
necesidad de empleo asalariado, sea agrícola o no agrícola. Además, en México reduce las migraciones. ${ }^{14}$ Por su parte, la crianza de ganado, que requiere relativamente menos mano de obra, eleva la participación del hogar en el ingreso por concepto de ERNA, y la presencia de un miembro adicional acrecienta la probabilidad de ingresos por concepto de salarios.

Por otra parte, en Honduras la participación en el empleo por cuenta propia es relativamente independiente del tamaño o uso de la propiedad agrícola, pero la participación asalariada en el ERNA guarda directa relación con el tamaño del predio, particularmente en el norte del país — donde se ha instalado la mayoría de las zonas francas industriales-y cuando parte de las tierras del hogar son regadas y la mecanización reduce la necesidad de mano de obra (Ruben y Van den Berg, 2001).

Una posible interpretación de esta dispar realidad podría ser la de que, dependiendo de la localización y las "distancias", los hogares que poseen tierras suficientes como para originar excedentes con fines de reinversión invierten en ERNA cuando están bien localizados, o en la agricultura y en terrenos adicionales, cuando enfrentan limitaciones impuestas por la distancia.

\section{b) El ahorro y el acceso a crédito}

El mal funcionamiento de los mercados financieros en las zonas rurales de los países en desarrollo no sólo se debe a deficiencias de información, costos de transacción elevados y derechos de propiedad mal definidos que limitan el acceso al crédito formal, sino también a la inadecuada captación del ahorro de los hogares rurales. Esto impide a menudo que esos ahorros tengan una rentabilidad positiva, a menos que se les invierta en una empresa casera (Lanjouw, 2001). Así, el ingreso rural no agrícola puede provenir de ahorros invertidos, aunque al mismo tiempo con frecuencia se procura obtener ingresos del ERNA para superar las restricciones de crédito.

En concordancia con lo anterior, en El Salvador la gran mayoría de las empresas rurales no agrícolas declara que su capital inicial provino del ahorro personal. En rigor, originalmente sólo un 7\% de las empresas se financió mediante créditos institucionales (Lanjouw, 2001). En Perú, el acceso a crédito es un

\footnotetext{
14 La migración al resto de México o a los Estados Unidos está altamente relacionada con tener menos de tres años de enseñanza básica, en el primer caso, y más de esos tres años en el segundo (Yúnez-Naude y Taylor, 2001).
}

factor decisivo del empleo por cuenta propia (sea en el sector agrícola o en el no agrícola), mientras que en Honduras la búsqueda de empleo rural asalariado no agrícola, con los costos de transporte pertinentes, o los recursos para iniciar actividades de ERNA, generalmente se financian con cargo al ahorro personal o del hogar, o mediante crédito informal. Dicho de otra manera, sin ahorro ni acceso a crédito formal o informal difícilmente se puede acceder al ERNA, ya sea debido a costos de búsqueda o a la inversión requerida. Con todo, es importante destacar que, al igual que en otros países, en Perú y Honduras las fuentes de ingreso no agrícolas son un sustituto del crédito formal, extremadamente restringido, y alivian las restricciones de capital (Escobal, 2001; Ruben y Van den Berg, 2001).

Por lo general, los estudios sobre el ERNA tienen presente en sus análisis, de manera implícita, el empleo por cuenta propia o el empleo asalariado en microempresas o en empresas pequeñas. ${ }^{15}$ En consecuencia, no destacan lo suficiente el empleo en servicios gubernamentales (educación, difusión, asistencia técnica, servicios sociales, administración local, etc.), cuyos costos de búsqueda difieren de los que requiere el empleo en el sector privado. Reardon, Berdegué y Escobar (2001) sostienen que en los países latinoamericanos examinados el ERNA del sector público generalmente es bastante bajo. No nos convence que esto sea así, y habría que investigar más a fondo este punto. En Chile, por ejemplo, el empleo vinculado al gobierno representa un nada despreciable $16 \%$ del ERNA total (educación, 8\%; administración pública incluido defensa, $6 \%$, y servicios sociales y de salud, $2 \%$ ). En Brasil, alrededor de $70 \%$ de las personas que trabajan en la categoría de "servicios sociales" prestan servicios en las escuelas públicas y $8 \%$ en la salud pública. El resto trabaja en organizaciones deportivas, clínicas y escuelas privadas y distintos tipos de servicios de asistencia social (Graziano da Silva y del Grossi, 2001).

\section{c) Educación y experiencia}

No hay duda alguna de que la relación entre la educación y el tipo de ERNA mejor remunerado es

\footnotetext{
15 Wiggins (2003) destaca que clasificar las actividades en "asalariadas" o "por cuenta propia" puede ser inadecuado, puesto que muchos empleos por cuenta propia se ajustan de tal manera a las necesidades del cliente que equivalen a trabajo asalariado. A continuación, el autor cita el ejemplo del peón y del pintor, cada cual aporta sus propias herramientas (el machete y la brocha, respectivamente), a ambos se les paga por día, los dos generalmente son dirigidos por el contratista en cuanto a algunas especificidades del trabajo y mientras que a uno se le considera obrero asalariado, al otro se le clasifica como trabajador por cuenta propia.
} 
positiva, ya que todos los estudios apuntan en la misma dirección. Sin embargo, por lo general el ERNA menos productivo no acusa una correlación significativa con los niveles educativos, pese a que los conocimientos técnicos y la experiencia indudablemente constituyen activos.

En el noreste de Brasil, la probabilidad de participar en el ERNA entre quienes han completado la enseñanza básica ${ }^{16}$ es dos puntos porcentuales más alta que entre los analfabetos, manteniendo constantes las demás variables. Para quienes han completado la enseñanza secundaria, esta probabilidad es 24 puntos porcentuales más alta. Iguales tendencias se observan en el sureste de Brasil. Esto queda aún más de manifiesto cuando dentro del ERNA se distingue entre actividades de mayor productividad y de baja productividad (Ferreira y Lanjouw, 2001).

En México, la relación positiva entre educación e ingresos (procedentes estos últimos tanto de la agricultura como del ERNA) se torna particularmente manifiesta cuando el hogar tiene un miembro adicional con más de nueve años de educación formal. Esto da lugar a que el ingreso asalariado registre un aumento marcado, equivalente a unos 780 dólares. En cambio, tener en el hogar un miembro más con enseñanza básica incompleta (1 a 3 años de escolaridad) se relaciona con la producción de bienes de primera necesidad, ya que con estos niveles educativos no tiene más alternativa que dedicarse a una actividad tradicional, como el cultivo del maíz (Yúnez-Naude y Taylor, 2001).

En Ecuador, el nivel educativo también guarda relación directa con el ERNA. Los hogares tienen mayores probabilidades de trabajar en empresas rurales no agrícolas cuando al menos uno de sus miembros tiene educación formal básica o secundaria. Además, si todos los miembros del hogar tienen alguna escolaridad, es mucho más probable aún que se dediquen a una actividad rural no agrícola, mientras que los que cursaron estudios postsecundarios tienen más probabilidades de desempeñarse en un trabajo asalariado que de establecer una empresa familiar (Elbers y Lanjouw, 2001).

En Perú, los efectos de la educación también son claros: a mayor escolaridad, menor es la inclinación a

${ }^{16}$ Cabe señalar que Brasil exhibe uno de los niveles medios de educación rural más bajos de América Latina y que en el noreste del país ellos son aún peores. En promedio, $63 \%$ de la población rural brasileña de 15 a 24 años de edad tiene cinco años o menos de enseñanza básica, y en el grupo etario de 25 a 59 años, el $83 \%$ ha asistido cinco años o menos a la escuela (CEPAL, 2001). obtener ingresos de las tierras de la familia y mayor el estímulo a destinar su tiempo al ERNA, ya sea por cuenta propia o en forma asalariada. Las estadísticas revelan que los ingresos de la mano de obra especializada en la agricultura son $30 \%$ más altos que los de la mano de obra agrícola no especializada, y alrededor de 50\% más altos que los del ERNA. Sin embargo, esta diferencia sólo se observa en la costa, mientras que en el altiplano y en el Amazonas prácticamente no hay diferencia. Escobal (2001) lo atribuye a que en estas regiones el mercado de trabajo está relativamente poco desarrollado.

En Nicaragua, las personas que no poseen tierras pero que tienen un nivel educativo alto, en especial las que viven cerca de caminos y pueblos, obtienen altos ingresos del ERNA en actividades como la enseñanza (Corral y Reardon, 2001).

Cabe señalar que en el caso del ERNA parece aplicarse lo mismo que había concluido Schultz (1964) respecto de la agricultura en general, y posteriormente, Figueroa (1986) respecto de América Latina: esto es, que la rentabilidad de un año adicional de educación no es la misma en una zona pobre y aletargada que en una más rica y dinámica. Así, Berdegué, Ramírez y otros (2001) encontraron que los trabajadores con nivel educativo más alto de Portezuelo (municipio rural poco dinámico) generalmente realizaban las mismas labores que aquellos con menor nivel educativo de Molina (municipio rural dinámico), y que en este último las personas con más educación tenían más oportunidades. En rigor, cifras correspondientes a varios países latinoamericanos revelan que quienes trabajan primordialmente en el ERNA tienen más años de escolaridad que los residentes rurales dedicados principalmente a la agricultura, pero que sus años de escolaridad son similares a los de residentes urbanos que se desempeñan sobre todo en faenas agrícolas. En cambio, los residentes urbanos que trabajan principalmente en actividades no agrícolas exhiben niveles educativos más elevados. ${ }^{17}$

\section{d) Los miembros del hogar}

En muchos lugares, el hogar campesino es una importante unidad de toma de decisiones. Se caracteriza por ser a la vez productor y consumidor de un conjunto de bienes, como los alimentos y el tiempo de sus miembros (utilizado para el trabajo o para el es-

\footnotetext{
${ }^{17}$ Resultados de tabulaciones especiales de encuestas de hogares realizadas en la CEPAL.
} 
parcimiento). Teóricamente, el hogar "maximizará" en un proceso en dos etapas que es repetido y, por lo tanto, separable. Primero, maximizará sus utilidades como productor, lo que maximizará sus ingresos; y a continuación, distribuirá sus ingresos de manera de maximizar su utilidad como consumidor. La divisibilidad del proceso de maximización depende de si hay o no diferencias entre los precios de mercado de los bienes de producción/consumo y el valor de ellos para el hogar (los precios de cuenta). La endogeneidad de los precios de cuenta ${ }^{18}$ puede darse en una amplia gama de circunstancias. Está presente potencialmente cuando el mercado de al menos uno de los bienes de producción o consumo es "imperfecto", es decir, cuando el hogar no es tomador de precios, considera que el producto vendido o comprado en el mercado es un sustituto imperfecto del bien producido y utilizado en la granja, o debe hacer frente a diferencias entre el precio de compra y el de venta originadas por los costos de transacción. La endogeneidad señalada también se da cuando el trabajo del hogar en la agricultura o fuera de ella no cumple igual función de utilidad. Y lo mismo sucede cuando ninguno de sus miembros trabaja en labores no agrícolas, pese a su opción de hacerlo, en un contexto en que la mano de obra familiar y la asalariada son elementos independientes de la función de producción del hogar (Löfgren y Robinson, 1999).

Al parecer, tanto en Honduras como en El Salvador los hogares utilizan primero la mano de obra familiar para la autoproducción de sus alimentos de primera necesidad y sólo después comprometen a sus "miembros supernumerarios" en el ERNA. En consecuencia, el tamaño del hogar influye positivamente en la probabilidad de que uno de sus miembros participe en el ERNA. Tal participación es importante como estrategia para diversificar los ingresos del hogar cuando éste dispone de recursos suficientes para reemplazar a los miembros que tienen más educación, los que pueden ganar más fuera de la agricultura (Lanjouw, 2001, y Ruben y Van den Berg, 2001).

Por el contrario, en Brasil el tamaño del hogar no parece guardar relación directa con la participación en el ERNA y los datos incluso indican que el hogar que se especializa en actividades agrícolas (esto es, en que un porcentaje ya elevado de sus miembros trabaja en la agricultura) tiene pocas probabilidades de que uno

\footnotetext{
${ }^{18}$ Esto es, el hecho de que esos precios no sean determinados por el mercado, sino en forma endógena por la acción recíproca entre la oferta y la demanda del hogar.
}

de sus miembros se dedique a una actividad no agrícola (Ferreira y Lanjouw, 2001).

El tipo de ERNA principal varía en los distintos estratos de ingresos. Los hogares de ingresos medianos ${ }^{19}$ trabajan principalmente en faenas no agrícolas, los de ingresos altos trabajan por cuenta propia en actividades rurales no agrícolas o tienen empresas pequeñas y medianas que realizan labores de la misma índole, mientras que la mayoría de las familias pobres llevan a cabo actividades agrícolas asalariadas y obtienen algunos ingresos no agrícolas adicionales de la artesanía o del comercio menor. Esto guarda relación también con la acumulación de capital que generalmente se produce a lo largo del ciclo de vida y con las necesidades de capital del ERNA. El corolario de lo anterior es que, para aumentar su participación en el ERNA, los hogares rurales i) tienen que superar las barreras de entrada de índole financiera, y ii) tener acceso o posibilidad de acceso, desde el punto de vista de la inversión, a tecnologías que ahorran mano de obra, o iii) contar con una familia numerosa. La probabilidad de ingresar al ERNA aumenta con la edad hasta los 40 años, para luego disminuir, pese a que en Honduras los que ingresan al ERNA asalariado son generalmente personas con más años y la edad tiene un importante efecto positivo en el ingreso no agrícola, lo que posiblemente indique que el ERNA requiere a la vez más preparación y más experiencia. ${ }^{20}$

Por lo que respecta al género, las cifras para los once países latinoamericanos considerados revelan que los varones constituyen algo más que la mitad (56\%) del ERNA total. Sin embargo, como las mujeres se dedican mucho menos que los hombres a la agricultura (al menos según las cifras oficiales), la proporción de mujeres que trabaja en el ERNA en el total de la PEA femenina rural (alrededor de 51\%) es mucho más alta que la proporción de hombres (33\%). Por lo general, los hombres que no son jefes de hogar realizan actividades asalariadas, mientras que las mujeres y los hombres jefes de hogar tienden a trabajar por cuenta propia. Sin embargo, hombres y mujeres se desempeñan en subsectores diferentes. Los primeros trabajan sobre todo en la construcción, los transportes y la industria pesada, y las mujeres generalmente en labores administrativas, la industria textil, la educación, actividades

19 Este concepto es relativo, ya que en la América Latina rural el $38 \%$ de las familias vive por debajo de la línea de indigencia y $64 \%$ por debajo de la línea de pobreza (CEPAL, 2002).

${ }^{20}$ Ruben y Van den Berg (2001), Dirven (2000), Ferreira y Lanjouw (2001) y Corral y Reardon (2001). 
por cuenta propia y servicios personales y domésticos (cuadro 3). En general, las mujeres tienden más a trabajar por cuenta propia, pero usualmente, a igualdad de otras condiciones, ganan mucho menos que los hombres: hasta 29\% menos en El Salvador, por ejemplo, según señala Lanjouw (2001).

Al considerar otras características, se observa que en Brasil la probabilidad de participar en el ERNA parece no guardar relación con la raza, contrariamente a lo que sucede en otros países (Ferreira y Lanjouw, 2001). En México, a los indígenas les resulta más difícil acceder al ERNA que a los no indígenas con similar nivel educativo; además, entre ambos grupos se observa una importante disparidad educativa (de Janvry y Sadoulet, 2001). Más allá de atribuirse a simple discriminación, la que ciertamente existe, esto podría explicarse porque tiende a haber una significativa correlación entre la pertenencia a grupos indígenas y la residencia en zonas más alejadas, con baja densidad de población y menos ERNA (Corral y Reardon, 2001).

Otro hallazgo interesante, al menos en Brasil, es que las personas nacidas en el mismo municipio en que viven actualmente tienen una probabilidad levemente menor de participar en el ERNA (Ferreira y Lanjouw, 2001). Se puede trazar un paralelo entre esto y las conclusiones sobre la mayor apertura a la innovación (y sus riesgos) exhibida por los migrantes que regresan de Lima, la capital, en Perú y por los ex soldados o guerrilleros de Centroamérica y Colombia. La exposición a experiencias y actividades diferentes de las que habrían tenido en su aldea natal parece haber producido en ellos un cambio de mentalidad y capacidades que, entre otras cosas, afecta sus decisiones en materia de inversión y de trabajo.

\section{Bienes públicos, infraestructura y otros acti- vos derivados de la localización}

\section{a) El dinamismo en la agricultura}

La gran variedad de vinculaciones entre el sector no agrícola y el agrícola, así como las diferentes fuerzas tras ellas, han sido objeto de abundantes análisis teóricos y empíricos. Johnston y Kilby (1975), así como muchos otros autores, han sostenido que puede surgir un círculo virtuoso de la intensificación de las actividades agrícolas y no agrícolas, sobre la base de vinculaciones entre la producción y el consumo. No hay duda de que, en principio, ello es así y la mayoría de los estudios apunta en esa dirección. Sin embargo, las políticas de apertura al comercio y las inversiones externas que han aplicado en distinta medida todos los países de América Latina desde mediados del decenio de 1980, unidas al mejoramiento de la red de transporte, han acrecentado las posibilidades de fortalecer vinculaciones no locales que conduzcan a una "filtración" parcial de los efectos locales al "resto del mundo", es decir, a la economía nacional o a economías extranjeras. Sin embargo, también puede suceder lo contrario y haber mayores posibilidades de "motores" externos que originen dinamismos locales.

Compartimos la impresión de Elbers y Lanjouw (2001) de que el modelo tradicional de crecimiento en el cual Lewis apunta a las transferencias intersectoriales mantiene toda su validez cuando se reconoce que el sector no agrícola moderno puede desarrollarse igualmente bien en las zonas rurales y en las urbanas. Los datos indican que este proceso tiende a incrementar la inequidad, pero ello no significa que los pobres no se verán beneficiados. Además, no puede excluirse la posibilidad de que el sector agrícola sea la fuerza que subyace los cambios en materia de bienestar, a la vez que los cambios en los patrones del ERNA.

Varios de los autores de estudios examinados en este artículo comprobaron la existencia de algunas vinculaciones vigorosas. Escobal (2001) encontró que en Perú, mientras mayor fuera la productividad de la tierra en un distrito determinado - y en consecuencia, mientras más dinámico fuera el sector agrícola localmayor era la participación del ingreso no agrícola en el ingreso total del hogar. Por su parte, Ruben y Van den Berg (2001) llegaron a la conclusión de que las microempresas de Honduras tienen importantes vinculaciones con el sector agrícola, ya sea a través del suministro de insumos (eslabonamientos hacia atrás) o bien mediante la transformación o distribución de sus productos, principalmente a sus consumidores rurales (eslabonamientos hacia adelante).

Lanjouw (2001) se muestra más cauteloso y sostiene que en El Salvador, sobre la base de los datos disponibles, es difícil verificar el vigor de los eslabonamientos hacia atrás y hacia adelante que se deben al aumento del ingreso agrícola. Pero sí concluye que tanto las vinculaciones que se originan en la agricultura como aquellas provenientes del consumo están presentes porque, de alguna manera, parte importante de las actividades no agrícolas gira en torno al comercio, la preparación de alimentos, el transporte y las actividades de reparación.

En Chile, sin embargo, se observa que en dos municipios rurales diferentes (Molina, con una agricultura dinámica, y Portezuelo, con una agricultura mucho menos dinámica) los ingresos generados por el 
ERNA están menos vinculados con la agricultura en Molina que en Portezuelo (22\% y 57\%, respectivamente) y que, en promedio, los ingresos provenientes del ERNA son superiores cuando están menos relacionados con la agricultura. La verdad es que el ERNA directamente vinculado con la agricultura, como el empleo en las agroindustrias, genera ingresos equivalentes a entre $33 \%$ y $43 \%$ de los brindados por el ERNA que no tiene esta vinculación directa. Además, los ingresos provenientes de las actividades no agrícolas de los hogares rurales en zonas rurales sólo se aproximan al 70\% de los originados por las actividades de esos hogares en centros urbanos. Estas últimas, sin embargo, contribuyen a generar una importante afluencia de ingresos hacia las zonas rurales (Berdegué, Ramírez y otros, 2001).

Para explicar el tipo de vinculaciones que se producen, un estudio reciente sobre las aglomeraciones de empresas y las cadenas de valor de la industria láctea en varios países latinoamericanos (Dirven, 2001) mostró claramente la validez de la teoría decimonónica de von Thünen sobre la gradiente del valor de la tierra, por una parte, y la importancia del tipo de empresas (desde empresas micro, pequeñas, medianas y grandes de propiedad nacional a empresas transnacionales) que participan en cada nodo, por la otra. Así, cerca de las grandes ciudades, los predios productores de leche hacen uso mucho más intensivo de la tierra y, en consecuencia, de toda clase de insumos. Por lo tanto, tienen mucho más vinculaciones hacia atrás con la producción y los servicios que los predios lecheros de zonas más apartadas, aunque a menudo con importadores más que con productores locales de insumos. En segundo lugar, los procesos industriales también varían según la localización. Así, los bienes de más valor, como el yogur, el queso fresco y la leche líquida, se producen cerca de las ciudades más grandes, y los quesos maduros y la leche en polvo en zonas productoras de leche más apartadas, mientras que en las zonas tropicales estos dos últimos productos provienen de ganado que sirve para dos fines: la producción de carne y la de leche. Naturalmente, las vinculaciones resultantes con los proveedores de maquinaria, transporte, embalaje y otros insumos son muy diferentes. El hecho de que las granjas, agroindustrias o proveedores de insumos y servicios sean microempresas o empresas transnacionales - o empresas de cualquier tamaño intermedio - también tiene efectos significativos en el uso de tecnología y en las vinculaciones resultantes (Dirven, 2001). Hasta ahora, la literatura especializada se ha preocupado poco de integrar la agricultura y sus vinculacio- nes con los efectos de la distancia y de conocer el impacto combinado de ambas cosas en el ERNA.

\section{b) Los caminos y otro tipo de infraestructura}

En general, en América Latina el ERNA parece hallarse estrechamente relacionado con la localización. El nivel de los ingresos procedentes de actividades no agrícolas depende principalmente del contexto económico, en especial el dinamismo de la economía local o territorial, y también de la calidad de los caminos. El acceso a buenos caminos es particularmente importante para poder participar en el empleo asalariado agrícola y no agrícola. Sin embargo, en las actividades no agrícolas por cuenta propia este factor parece tener menos peso. Hasta ahora los datos disponibles indican que en estas últimas predominan empresas pequeñas administradas mayoritariamente por mujeres, que abastecen a mercados rurales locales (Berdegué, Ramírez y otros, 2001; Corral y Reardon, 2001).

En especial, todo indica que el ERNA es más dinámico en las zonas que tienen buenas conexiones con los mercados y que cuentan al menos con un mínimo de infraestructura (Ferreira y Lanjouw, 2001). ${ }^{21} \mathrm{En}$ consecuencia, el acceso a bienes públicos como la electrificación rural y los caminos eleva de manera apreciable los ingresos globales provenientes de la agricultura y particularmente de actividades no agrícolas (Escobal, 2001). Lo más probable es que esto no se deba a que los caminos sean menos importantes para la agricultura, sino más bien a que, según la "ley" de von Thünen, la agricultura se adapta a zonas menos próximas a los caminos principales, mientras que las actividades no agrícolas tienden a ubicarse más cerca de ellos y en la proximidad de concentraciones ruralurbanas (Corral y Reardon, 2001). Sin embargo, por lo general son pocas las empresas rurales que tienen acceso a infraestructura básica. Por ejemplo, en El Salvador, $35 \%$ de las empresas dijeron tener dificultades con el transporte debido al mal estado de los caminos, y eran muy pocas las que tenían teléfono. Y si bien es cierto que el acceso a infraestructura parecía influir en el ERNA de manera similar a la antes señalada y que el ERNA de baja productividad al parecer se concentraba más bien en torno a pequeños villorrios y otros asentamientos rurales, curiosamente esto no

\footnotetext{
${ }^{21}$ El juez anónimo que comentó este artículo destacó que a menudo las actividades más dinámicas dan lugar a inversiones en caminos y otro tipo de infraestructura y que, por lo tanto, hay que interpretar con cautela la relación de causa a efecto entre la infraestructura y el ERNA. La observación es sin duda pertinente.
} 
parecía pesar demasiado en las remuneraciones y, en el caso del ERNA de mayor productividad, la distancia no parecía tener mucha importancia (Lanjouw, 2001).
Cabe recordar sin embargo que, como se dijo antes y a diferencia de la mayoría de los países de la región, El Salvador está densamente poblado.

\section{VI}

\section{Las "distancias" y el empleo rural no agrícola}

\section{Territorios y localización}

Como puede deducirse de la sección anterior, y como ya se está comenzando a hacer en la región, las políticas de desarrollo rural y de mitigación de la pobreza rural deberían considerar de manera explícita la heterogeneidad de los territorios. Un estudio general reciente sobre el desarrollo territorial rural en América Latina (Schejtman y Berdegué, 2003) distinguió cuatro tipos de territorios, caracterizados por diferentes trayectorias y potencialidades históricas, socioeconómicas e institucionales, a los cuales es preciso aplicar políticas también diferentes. Ellos son: i) territorios que han progresado en materia de desarrollo productivo y que han alcanzado un desarrollo institucional que les permite un grado razonable de inclusión y diálogo sociales; ii) territorios que han experimentado un importante proceso de crecimiento económico, aunque éste ha influido poco en el desarrollo local y aún menos en las oportunidades de los segmentos más pobres; iii) territorios con instituciones vigorosas que suelen expresarse en una fuerte identidad cultural, pero carentes de opciones económicas propias que puedan sustentar procesos de largo plazo para mitigar la pobreza, y iv) territorios que atraviesan por un abierto proceso de desestructuración económica y social.

Esta tipología, que fue concebida para las políticas de desarrollo territorial, ciertamente es útil también para explicar los tipos de empleo rural no agrícola que se encuentran en dichos territorios, puesto que el ERNA influye en el territorio circundante y a la vez recibe su influencia. Uno de los inconvenientes de esta tipología, sin embargo, es que sus autores no tomaron expresamente en cuenta el factor localización, es decir, la distancia a que se encuentran los mercados. Poco a poco - y bajo la influencia de Krugman, entre otros - los economistas han comenzado a reexaminar la localización como factor del desarrollo económico.

Wiggins y Proctor (2001) lo expresan de esta manera: 'En torno a la mayoría de las ciudades hay una zona periurbana que interactúa intensamente con la ciudad, zona que podría definirse como aquella en la cual las personas pueden trasladarse diariamente entre la aldea y la ciudad para trabajar. Más allá está el campo, desde el cual la distancia impide el traslado diario y en que el costo de viajar hacia y desde la ciudad es significativamente mayor. Más lejos aún, hay zonas rurales de acceso difícil debido a la falta de infraestructura, a las grandes distancias y a obstáculos físicos. En este caso, el costo del traslado de bienes y personas hacia y desde las zonas urbanas es extraordinariamente elevado. ${ }^{22}$ Cabe señalar que la densidad del asentamiento generalmente guarda relación directa con su proximidad a las ciudades (y la riqueza natural de la zona). ${ }^{23}$ En seguida, los autores citados superponen la calidad de los recursos naturales a las zonas periurbanas, al campo situado a distancia mediana y a las zonas rurales muy apartadas, y configuran así un cuadro con seis categorías de localizaciones y recursos (calidad del terreno, belleza del paisaje, etc.). Estas categorías indican la probabilidad de encontrar ciertos tipos de actividades en determinados lugares (o desde otro punto de vista, las posibilidades de desarrollo del territorio). El monto y control de los activos, sobre todo la tierra, también tienen un papel importante, especialmente en el caso de América Latina por su muy asimétrica distribución de ingresos y activos.

\section{Las “distancias" y los costos de transacción}

La localización es crucial porque, junto con la infraestructura, determina la distancia hasta los mercados,

\footnotetext{
22 Incluso puede darse el caso de que los mercados "fallen" para cierto individuo u hogar, cuando la diferencia entre el precio de venta y el precio de compra de un bien determinado es demasiado grande. En estos casos, es posible que al hogar le convenga más producir el bien para su propio consumo (Escobal, 2000; Key, Sadoulet y de Janvry, 2000).

${ }^{23}$ Esta cita de Wiggins y Proctor (2001) fue traducida del inglés, junto con el resto del presente artículo, por los servicios de la CEPAL. Se reproduce entre comillas simples, no dobles, para indicar que no corresponde a una traducción oficial de la obra citada.
} 
entendiendo aquí por distancia la lejanía física ponderada por los costos de transacción. Un estudio en Perú (Escobal, 2000) calculó los costos de transacción de la venta de productos agrícolas, en este caso papas, en dos distritos de Huancavelica. En promedio, esos costos eran cercanos al 50\% del valor de los productos vendidos. Además, eran $60 \%$ más altos para los campesinos conectados al mercado a través de un sendero que para aquellos que contaban con un camino apto para vehículos y transitable todo el año. El mismo estudio confirmó que los costos de transacción eran muy superiores para los pequeños agricultores que para los que trabajaban a una escala mayor $(67 \%$ y $32 \%$ del valor de la venta, respectivamente).

Sin embargo, hay varias otras "distancias" que también influyen en los costos de transacción. Según Escobal (2000), las decisiones de los agricultores no sólo dependen del costo y del tiempo que tarden en llegar a un mercado, sino también de su experiencia en un mercado determinado, de la estabilidad de sus relaciones con los compradores y de los recursos invertidos para obtener información y para supervisar los arreglos contractuales implícitos.

Un estudio sobre la "distancia organizacional" efectuado en Perú reveló que las organizaciones e instituciones rurales tienen una marcada tendencia a relacionarse con entes de su misma naturaleza, lo que sugiere que sus profesionales y técnicos no miran a las organizaciones comunitarias como sus iguales. Esta tendencia a relacionarse con los pares introduce un factor de exclusión adicional de los pobres y de los "más rurales" (Andersen, 2003).

Las "distancias" sociales y culturales ${ }^{24}$ cumplen asimismo una función esencial en las transacciones de bienes, mano de obra, servicios e ideas. Además, en esta interacción bidireccional de causas y efectos, la ubicación de los hogares dentro del villorrio, distrito o región también es crucial. El aislamiento social y económico que puede resultar de estas distintas "distancias" puede ser bastante acentuado, incluso entre hogares de una misma localidad, dada la gran dispersión que muestran muchas localidades rurales. Además, como las "distancias" aumentan las asimetrías de información, los pobres y las personas que viven aisladas — que de por sí tienen pocas alternativas en cuanto a dónde, con quién y a qué precio comerciar- par-

\footnotetext{
${ }^{24}$ Primi (2002) entiende por distancia cultural las diferencias de idioma, lógica, ideas, convicciones y valores entre los distintos hogares, grupos sociales y localidades.
}

ticiparán en los diversos mercados en condiciones desiguales (Primi, 2002).

En suma, la decisión de ofrecer o utilizar recursos laborales o de inversión para el ERNA y no para la agricultura o la migración tiene que ver con el salario o ingreso esperado, menos los costos de transacción (información, "supervisión del contrato" o riesgo de que el contrato esperado no se materialice o se suspenda tempranamente, transporte propio o de los bienes producidos hasta el mercado, etc.). La combinación de costos de transacción en cada caso dependerá de cada persona o familia (su capital humano, capital social, experiencia, información acumulada y canales de información), de las características locales específicas y de cada mercado (Escobal, 2000). Los distintos tipos de "distancias" desempeñan en esto un papel esencial.

\section{Los ingresos provenientes del erna y la gradiente de actividad}

Volviendo a la concepción más económica de la "distancia" (es decir, la de los costos de transacción mediados por la distancia física), la información disponible sobre el ERNA es aún escasa, pero no hay duda de que la distancia y los costos de transacción consiguientes influyen directa e indirectamente en él, ya sea por la indivisibilidad de los bienes de producción-consumo a nivel del hogar, o porque si el ERNA tiene vinculaciones al menos en parte con la agricultura y con el consumo de bienes y servicios por los hogares agrícolas, el efecto de la "distancia" en la agricultura y sus productos también debería influir en el ERNA.

Reardon, Berdegué y Escobar (2001) llegaron a la conclusión de que la proporción del ingreso originada por el empleo rural no agrícola asalariado y por los servicios tiende a aumentar cuando se pasa de los territorios rurales del interior a zonas rurales próximas a pueblos y con buenos caminos. A su juicio, esto demuestra empíricamente las dificultades con que tropiezan las pequeñas empresas manufactureras rurales para competir con las manufacturas urbanas o importadas y la razón por la cual tales empresas generalmente sólo sobreviven en zonas apartadas. A igual conclusión llegó Renkow (1998), esto es, que la construcción de caminos es una medida de doble filo, que mejora la movilidad en ambos sentidos y amenaza con desplazar las manufacturas y servicios locales. Reardon, Berdegué y Escobar (2001), por su parte, sostienen que estos efectos merecen mayor estudio, pero que a primera vista parece probable que a medida que mejore la infraestructura caminera en las zonas rurales de América 
Latina y éstas queden mejor conectadas con los mercados nacionales e internacionales, el ERNA tenga cada vez más el carácter de asalariado y de servicios.

Concordando en gran medida con la descripción que hacen Wiggins y Proctor (2001) de las distintas zonas rurales, el Instituto Brasileño de Geografía y Estadística (IBGE) divide las zonas rurales en cuatro categorías. Pese a que en Brasil las "zonas exclusivamente rurales" (con población dispersa, menos de dos servicios comunitarios como escuela, iglesia o centro de salud, y ausencia de centros comerciales o de fábricas) albergan el $82 \%$ de la población rural ocupada, sólo representan un 59\% del ERNA. Esto indica que el ERNA está estrechamente relacionado con los centros de comercio y con la infraestructura básica que generalmente los acompaña. Los datos sugieren también que las actividades manufactureras (y otras conexas) no se concentran específicamente en los centros más urbanizados, contrariamente a lo que sucede con las actividades comerciales. Vemos así que la localización influye en las probabilidades de participar en el ERNA, incluso después de considerar todas las demás características (Ferreira y Lanjouw, 2001). Estos mismos autores concluyen que es muy probable que las economías de los pueblos más pequeños estén más directamente relacionadas con la economía rural que con las economías de zonas urbanas más importantes.

Por lo que toca a la mayor dependencia de la economía rural que exhiben las ciudades más pequeñas y a la inversa, Wiggins (2003) sostiene que, salvo raras excepciones, los bienes y servicios producidos por el ERNA provienen de materias primas locales y se venden localmente. En consecuencia, en la cadena de oferta a menudo intervienen no más de dos o tres actores que generalmente viven en la misma localidad, se conocen bien y comercian cara a cara.

Los ingresos mensuales per cápita disminuyen cuando se pasa de las zonas urbanas a las zonas rurales, y entre estas últimas, desde las zonas de actividades múltiples a las más especializadas en la agricultura; esto se observa tanto para los hogares que dependen exclusivamente de la agricultura como para aquellos que dependen de actividades múltiples. Además, los ingresos per cápita varían de una región a otra, observándose que en Brasil los ingresos más altos corresponden a las zonas rurales del estado de São Paulo y los más bajos a las regiones del noreste y el sudeste del país (Graziano da Silva y del Grossi, 2001).

De Janvry y Sadoulet (2002) ${ }^{25}$ examinaron los factores que determinan en México el crecimiento del

${ }^{25}$ Citados por Schejtman y Berdegué (2003). empleo en la manufactura y los servicios en municipios rurales y semiurbanos (de 15 mil habitantes o menos). Encontraron que la proximidad a centros urbanos de 250.000 o más habitantes, el contexto regional y la calidad de las conexiones entre las zonas rurales y urbanas explicaban $94 \%$ y $67 \%$ del crecimiento de dicho empleo en los municipios rurales y semiurbanos, respectivamente

En El Salvador, Honduras y Nicaragua, el ERNA varía significativamente de una zona a otra, y se concentra principalmente en torno a la capital y en otras zonas particularmente dinámicas o densamente pobladas. Así, en la zona central de El Salvador (que incluye la capital, San Salvador) alrededor de 50\% de la PEA rural trabaja en el ERNA, mientras que en el oriente la cifra sólo alcanza a $23 \%$, aunque en todas las regiones la gama de actividades del ERNA es relativamente similar y la localización geográfica no parece influir demasiado en las remuneraciones (Lanjouw, 2001). En Nicaragua, el ingreso rural no agrícola tiende a concentrarse en las zonas rurales en torno a la capital, Managua; en los hogares de mayor nivel educativo de las zonas rurales densamente pobladas del Pacífico, que cuentan con buenos caminos y están cerca de los pueblos, ciudades y puertos principales; y en el cuartil de hogares rurales con mayores ingresos. En cambio, las zonas del interior se limitan a pequeñas manufacturas, mercados locales de escasa actividad y ocupaciones en el ERNA con bajas remuneraciones (Reardon, Berdegué y Escobar, 2001). En Honduras, el empleo asalariado no agrícola es particularmente importante en el norte, donde se han establecido zonas libres industriales en las proximidades de San Pedro Sula y cerca de Puerto Cortez, que han dado empleo a unas 50.000 personas, especialmente mujeres jóvenes. En las aldeas rurales, el empleo asalariado no agrícola en pequeñas industrias o servicios tiene particular importancia. El trabajo por cuenta propia es más común en el sur del país, donde los servicios de distribución son relativamente satisfactorios; incluye servicios, artesanías, elaboración de alimentos y comercio, todas ellas actividades que para ser sostenibles requieren mayor densidad de población. Las personas sin tierras y las que viven en caseríos rurales generalmente son las que registran mayor participación en el ERNA. A su vez, los agricultores que viven en pequeños villorrios rurales tienden a recurrir a sistemas de producción que hacen uso relativamente más alto de insumos (Ruben y Van den Berg, 2001).

En Perú, el cultivo de tierras propias sigue siendo la principal fuente de ingreso de la mayoría de los hogares rurales. Debido a que las zonas costeras son 
más ricas, cuentan con una red vial más densa y tienen mejor acceso a mercados y ciudades, se esperaba encontrar en ellas más empleo asalariado dentro de la distribución laboral de los hogares. Sin embargo, los datos revelan que no hay grandes diferencias entre los patrones regionales del empleo asalariado agrícola y el ERNA y entre el empleo asalariado y el empleo por cuenta propia. En realidad, se comprobó que los ingresos rurales no agrícolas de asalariados y trabajadores por cuenta propia eran más importantes en las regiones más pobres, seguramente por factores de presión. Esto contrasta con las acentuadas diferencias entre regiones del ingreso per cápita, que coinciden con amplias disparidades de salarios agrícolas (en las zonas costeras se pagan salarios más altos). Los salarios reflejan las diferencias de productividad de la agricultura entre la costa y el altiplano, debidas al clima y al tamaño de los predios. Sin embargo, en el ERNA las diferencias de productividad no son tan marcadas (Escobal, 2001).

En Ecuador, la encuesta de hogares realizada en 1995 también desagregó los datos relativos a las zonas rurales, esta vez en tres categorías. Contrariamente a lo que sucede en Brasil, México y Centroamérica, la gente que vive en la periferia de las ciudades, y también en zonas dispersas, de Ecuador tiene menos probabilidades de participar en el ERNA, en ocupaciones de mayor o de menor productividad, que la que vive en zonas rurales "amanzanadas" (asentamientos que cuentan con alguna infraestructura básica pero que tienen menos de 5.000 habitantes). Elbers y Lanjouw (2001) sostienen que en el caso de las zonas dispersas esto no resulta tan sorprendente, puesto que en ellas las probabilidades de que los hogares trabajen en la agricultura son mayores. Sin embargo, en vista de las oportunidades de empleo no agrícola que ofrecen los centros urbanos, la incidencia relativamente baja del ERNA en la periferia urbana desconcierta. Además, en la periferia hay más pobreza que en las zonas "amanzanadas" o que en las zonas urbanas. A juicio de los autores citados, en Ecuador las zonas periurbanas funcionan como asentamientos transitorios para residentes rurales que desean establecerse en zonas urbanas. En estas circunstancias, pocos estarían dispuestos a invertir lo requerido para acceder a empleo por cuenta propia. La segunda razón es que la proximidad de los grandes mercados urbanos induce a trabajar la tierra en forma intensiva. Por último, otra razón, no examinada por dichos autores, es que muchos migrantes recientes a zonas periurbanas trabajan como temporeros agrícolas. Por ejemplo, Hataya (1992) explicó que en Manizales, Colombia, los migrantes adul- tos de primera generación generalmente sólo estaban en condiciones de desempeñarse en ocupaciones menores, informales, debido a carencias educativas o de documentación (falta de certificados de nacimiento, de situación militar u otros). Por lo tanto, podían ganar más en empleos agrícolas transitorios (principalmente la recolección del café). Sus hijos, en cambio, realizaban durante las vacaciones trabajos agrícolas asalariados, que no tienen grandes barreras al ingreso, pero aspiraban a encontrar un empleo urbano formal después de terminar la escuela.

A diferencia de lo que sucede en el vecino Perú, en Ecuador la población de la costa tiene mayores probabilidades que la de las tierras altas de trabajar en el ERNA. Sin embargo, la diferencia no es significativa en el caso del ERNA mejor remunerado, lo que indica que la costa tiene una mayor proporción de ERNA poco productivo. Esto coincide con lo encontrado por el Banco Mundial (1995): que en la costa ecuatoriana las personas pobres trabajan principalmente en actividades asalariadas agrícolas y no agrícolas, mientras que en las tierras altas hay mayores probabilidades de que los pobres se dediquen a la agricultura de subsistencia. En el este, la probabilidad de participar en el ERNA es menor que en las tierras altas, particularmente cuando se trata de ocupaciones de baja productividad (Elbers y Lanjouw, 2001).

En su estudio sobre el ERNA en Chile, Berdegué, Ramírez y otros (2001) fueron al parecer los primeros en preocuparse del lugar en que trabajan efectivamente las personas que viven en las zonas rurales. Encontraron que tanto en una zona con agricultura dinámica como en una zona con agricultura en crisis, cerca de la mitad de las personas que se desempeñaban en el ERNA se trasladaba diariamente al trabajo en un pequeño pueblo vecino. Este es un hallazgo muy importante al que debería prestarse mucha atención en futuros estudios de casos: si no correspondiese sólo a una situación particular de estos dos municipios de Chile o a alguna característica singular del país, sino que fuese aplicable a la mayoría de los países de América Latina -y quizá incluso de otras regiones - llevaría a enfriar el entusiasmo despertado hasta ahora por el ERNA como estrategia para reactivar las áreas rurales. Los ejemplos anteriores muestran también que, salvo escasas excepciones, el ERNA es más frecuente y más dinámico cerca de las zonas más densamente pobladas o que están bien conectadas con las ciudades. Esto arroja también nueva luz sobre el ERNA y las políticas para estimularlo, así como sobre las posibilidades de éxito de tales políticas. 


\section{VII}

\section{Conclusiones y algunos temas}

\section{que merecen mayor estudio}

Desde el decenio de 1990 América Latina ha estado prestando creciente atención al empleo rural no agrícola. En la región, entre 30\% y $40 \%$ de los residentes rurales económicamente activos trabajan en el ERNA y más de $40 \%$ del ingreso rural proviene de fuentes no agrícolas. Sin embargo, los responsables de elaborar las políticas siguen orientando sus directrices y acciones en materia de desarrollo rural esencialmente hacia el sector agrícola. Habría que eliminar este sesgo, de modo que los esfuerzos de desarrollo rural fomentaran la creación de vinculaciones de producción y de servicios entre los "motores de crecimiento" — sean o no agrícolas- y la economía local, incluyendo en el concepto de economía local no sólo las zonas rurales propiamente tales sino también el territorio "natural" en que se encuentra incorporada la zona local y del cual se sienten parte los residentes locales, abarcando también el área en que se produce la mayor parte de las vinculaciones entre lo rural y lo urbano. Y como lo expresan Reardon, Berdegué y Escobar (2001), el reto que se plantea es el de movilizar inversiones y capacidades adicionales, tanto públicas como privadas, puesto que el ERNA no debería promoverse con recursos desviados de las actividades de desarrollo agrícola.

En el decenio de 1990, los países latinoamericanos aplicaron mayoritariamente políticas de descentralización y casi todos ellos dieron impulso a la infraestructura rural. Hasta ahora no se ha estudiado la influencia de estas medidas en los patrones de migración de los nuevos empleados públicos o del sector privado, ni de la población rural que busca nuevos trabajos. A su vez, las políticas de descentralización han permitido que los gobiernos locales influyan o participen en decisiones sobre planificación del uso de la tierra, educación, capacitación, infraestructura pública y otros asuntos, entre ellos la recaudación de impuestos y el otorgamiento de licencias, que tienden a convertirse en grandes barreras para ingresar al ERNA. Los gobiernos locales deberían aprovechar al máximo tales posibilidades. Por otra parte, particularmente en los países o regiones más pobres, los proyectos de desarrollo rural financiados por donantes multilaterales o bilaterales a menudo constituyen las principales ma- nifestaciones de las políticas públicas. Por lo tanto, debería entablarse un diálogo provechoso en pos de una visión común de las prioridades y las complementariedades y de los requisitos indispensables. También habría que estudiar la posibilidad de establecer alianzas con el sector privado, ${ }^{26}$ es decir, con aglomeraciones nacionales o transnacionales de empresas o incluso con empresas más pequeñas que tienen intereses en el territorio o en sus proximidades. Últimamente, algunas empresas importantes de la región se están preocupando cada vez más del efecto de sus actividades en el medio físico y de la imagen que se tiene de ellas. Además, algunas están aplicando criterios con mayor contenido social. Las autoridades nacionales y locales y la sociedad civil deberían fomentar y aprovechar decididamente estas actitudes.

Las cifras muestran claramente que algunos grupos de población están más representados que otros en el ERNA: las mujeres (respecto de su participación en la PEA rural), los con mayor nivel educativo y los jóvenes (hasta 40 años entre los varones y hasta alrededor de 30 años entre las mujeres). Habría que estudiar detenidamente el tema para saber cuál es la causa. Es posible que esto se deba en parte a la correlación entre juventud y años de escolaridad, puesto que los más jóvenes generalmente tienen más años de educación que la generación anterior; o bien a la falta de acceso a la tierra en mercados relativamente estáticos de este recurso y a usos y leyes que retardan la sucesión; o bien a horizontes más amplios que, sumados al debilitamiento de las tradiciones campesinas, dan a los jóvenes más libertad de elegir que la que tuvieron sus padres.

No cabe duda de que la dotación de bienes - tanto públicos como privados- también influye en el ERNA. Aunque las evidencias no siempre apuntan en una

\footnotetext{
${ }^{26}$ En Chile, la Fundación contra la Pobreza inició recientemente un proyecto para el cual buscó empresarios exitosos dispuestos a trabajar durante un año codo a codo con microempresarios, en reuniones periódicas de discusión, para asesorarlos en sus proyectos. La respuesta ha resultado inesperadamente positiva, en especial de parte de empresarios de la misma localidad que habían comenzado como pequeños empresarios algunas décadas antes.
} 
misma dirección, en la mayoría de los casos se encuentra una curva en U entre la participación de los ingresos del ERNA en el ingreso total y la dotación de activos (tierras, número y nivel educativo de los miembros del hogar, ahorro, etc.). En su mayoría, las personas con escaso acceso a activos que trabajan en el ERNA realizan tareas mal remuneradas y son motivados más bien por factores de presión y no de demanda, sea que trabajen por cuenta propia, como asalariados o - alternativa que no menciona ninguno de los estudios examinados- en ocupaciones no remuneradas. Debido a las características del lado izquierdo de la curva en $\mathrm{U}$, tanto respecto de los activos personales o del hogar como del tipo de actividad y las remuneraciones pertinentes, la promoción del empleo e ingreso rurales no agrícolas como medio de paliar la pobreza rural plantea grandes desafíos a las autoridades. No obstante, ellas deberían estar atentas al papel que desempeña el ERNA de baja productividad como red de protección para los pobres, y abstenerse de adoptar medidas que podrían socavarlo. Cabe señalar, además, que el último refugio contra la pobreza parece ser el trabajo agrícola asalariado.

De hecho, en América Latina todos los datos indican que el acceso al ERNA reduce la pobreza por dos vías diferentes, pero igualmente importantes. En primer lugar, al parecer las actividades con mayor productividad proporcionan ingresos suficientes para que eludan la pobreza los hogares con acceso limitado a la tierra. En segundo lugar, los segmentos más vulnerables de la población, como las mujeres, las minorías y muchos de los que viven en condiciones de pobreza extrema, tienden a concentrarse en el ERNA menos productivo; pero aun así, el ingreso adicional que suministran estas ocupaciones es de primordial importancia para impedir que se agrave la miseria.

Las zonas rurales más ricas y las más pobres deben ser objeto de trato diferente. En las primeras, es importante reducir los costos de transacción que confrontan tanto quienes realizan inversiones para dinamizar el ERNA como los hogares rurales que tratan de participar en él. Con miras a acrecentar el atractivo de estas regiones para el sector privado es preciso que el sector público cumpla una función importante (de construcción de caminos, electrificación, telecomunicaciones, riego) y que haga hincapié en inversiones públicas encaminadas a desarrollar en los hogares rurales (mediante la educación, el acceso a crédito, la activación de los mercados inmobiliarios, etc.) la capacidad de participar en una gama más amplia de actividades. En las zonas pobres, donde la relación con los mercados dinámicos es escasa o nula, es indispensable ser prudentes y no promover microempresas que terminen por ser un "ERNA de amparo" por no poder vincularse con los mercados dinámicos que demandan los bienes y servicios producidos por sus actividades (Reardon, Berdegué y Escobar, 2001). Al mismo tiempo, hay que tener presente lo señalado en el párrafo anterior.

Los estudios sobre el ERNA destacan en su mayoría la importancia de la infraestructura para el desarrollo rural. Sin embargo, al parecer es mejor contar con una infraestructura básica que combine servicios de comunicaciones, transporte, energía y agua sencillos e incluso rudimentarios, en vez de tener uno o incluso algunos servicios más complejos. En consecuencia, antes que intentos aislados sería más provechoso realizar un esfuerzo concertado de inversión pública (o privada) dirigido a un territorio determinado. Algunos estudios han demostrado que esto debería acompañarse de acceso al crédito y a tecnología (o asistencia técnica). Por último, otros estudios señalan que habría que focalizar todos los esfuerzos en un grupo de población que esté suficientemente abierto al cambio (a menudo por debajo de cierta edad y por encima de determinado nivel educativo). Lamentablemente, esfuerzos concertados de esta índole que se orientan a subgrupos de población específicos suelen ser difíciles, si no imposibles, de definir (y luego coordinar) entre diversos organismos públicos habituados a trabajar en forma sectorial e independiente. Además, tales esfuerzos de focalización se contraponen con los intereses de políticos locales, y con frecuencia también nacionales, cuya reelección depende de la amplitud de su electorado, y también van en contra del sentido de oportunidad en la programación de las políticas y los proyectos, pues no todos tienen la visibilidad deseada ni fructifican en el momento político preciso. El tira y afloja entre impacto y real politik es arduo. Pero si se busca el desarrollo y la mitigación de la pobreza, hay que optar por el impacto.

Los especialistas en desarrollo rural están comenzando a preocuparse del territorio y de su heterogeneidad al efectuar sus análisis y elaborar políticas de desarrollo, y los economistas empiezan lentamente a ver la localización como un factor que explica el crecimiento, la aglomeración de las actividades económicas y otros procesos. Sin embargo, de alguna manera, hasta ahora no se ha considerado cabalmente la localización dentro de las zonas rurales ni las "distancias" (de los mercados, la información, las organizaciones, así como de los conceptos, la lógica y los valores) 
inherentes a ella. Estos aspectos tienen particular importancia en América Latina, donde la densidad de la población rural es baja y la infraestructura y los servicios rurales no satisfacen las necesidades humanas y productivas básicas. La mayoría de los artículos sobre el ERNA latinoamericano examinados en el presente artículo parecen poner de manifiesto una asociación estrecha entre la localización y el tipo y dinamismo del ERNA, pero en general los autores no llegan a relacionar este aspecto con sus demás hallazgos, ni a señalar la localización como quizá el principal factor explicativo.

Siguiendo el mismo razonamiento, habría que prestar mayor atención al tipo de vinculaciones que emanan de la agricultura extensiva en contraposición a la intensiva; de las agroindustrias y otras actividades relacionadas o no con la agricultura; de los agentes económicos (desde microempresas hasta transna- cionales) que se dedican a ellas en relación con la localización y las "distancias" (desde las físicas hasta las sociales) y con la creación de ERNA a nivel local, o la generación de "filtraciones al resto del mundo". Ciertamente, hay margen para aplicar políticas destinadas a fomentar vinculaciones de carácter más local y, en consecuencia, también más ERNA.

Por último, es indispensable analizar más a fondo el traslado diario al trabajo de residentes rurales hacia zonas urbanas y viceversa, los patrones de migración rural-rural y su relación con el acceso a la infraestructura y los servicios públicos, y el empleo rural no agrícola. Lo más probable es que los resultados de ese análisis modifiquen sustancialmente lo que sabemos hasta ahora sobre el ERNA, lo que a su vez tendrá efectos en las políticas.

(Traducido del inglés)

\section{Bibliografía}

Andersen, J. (2003): Redes interorganizacionales e intervenciones en la salud, documento presentado en el Seminario "Capital social, herramienta para los programas de superación de la pobreza rural y urbana" (Santiago de Chile, CEPAL, 8 y 9 de enero de 2003), Pontificia Universidad Católica del Perú.

Banco Mundial (1995): Ecuador Poverty Report, Report N $14533-$ EC, Washington, D.C.

BID/FAO/CEPAL/RIMISP (Banco Interamericano de Desarrollo/Organización de las Naciones Unidas para la Agricultura y la Alimentación / Comisión Económica para América Latina y el Caribe / Red Internacional de Metodología de Investigación de Sistemas de Producción) (2004): Empleo e ingresos rurales no agrícolas en América Latina, serie Seminarios y conferencias, $N^{\circ} 35$, LC/2069-P, Santiago de Chile, CEPAL, abril. Publicación de las Naciones Unidas, $\mathrm{N}^{\circ}$ de venta: S.04.II.G.12.

Berdegué, J., E. Ramírez y otros (2001): Rural nonfarm employment and incomes in Chile, World Development, vol. 29, $\mathrm{N}^{\mathrm{o}} 3$, edición especial, Amsterdam, Elsevier Science.

CEPAL (Comisión Económica para América Latina y el Caribe) (2001): Panorama social de América Latina, 1999-2000, LC/G.2068-P, Santiago de Chile. Publicación de las Naciones Unidas, $\mathrm{N}^{\mathrm{o}}$ de venta: S.00.II.G.18.

(2002): Panorama social de América Latina, 2001-2002, LC/G.2183-P, Santiago de Chile. Publicación de las Naciones Unidas, $\mathrm{N}^{\mathrm{o}}$ de venta: S.02.II.G.65.

CEPAL/CELADE (Comisión Económica para América Latina y el Caribe/División de Población de la CEPAL-Centro Latinoamericano y Caribeño de Demografía) (1999): Población económicamente activa, 1980-2025, Boletín demográfico, $\mathrm{N}^{\circ} 64$, LC/G.2059, Santiago de Chile.

CNUAH (Centro de las Naciones Unidas para los Asentamientos Humanos) (1996): An Urbanizing World: Global Report on Human Settlements, 1996, HS/382/95/E, Oxford, Oxford University Press.

Corral, L. y T. Reardon (2001): Rural nonfarm incomes in Nicaragua, World Development, vol. 29, No 3, edición especial, Amsterdam, Elsevier Science.
De Janvry, A. y E. Sadoulet (1993): Rural Development in Latin America: relinking poverty reduction to growth, en M. Lipton y J. Van der Gaag, Including the Poor, Washington, D.C., Banco Mundial.

(2001): Income strategies among rural households in Mexico: the role of off-farm activities, World Development, vol. 29, No 3, edición especial, Amsterdam, Elsevier Science.

(2002): World poverty and the role of agricultural technology: direct and indirect effects, Journal of Development Studies, vol. 38, ํ 4, abril, Londres, Frank Cass \& Co.

Deininger, K. y P. Olinto (2001): Rural nonfarm employment and income diversification in Colombia, World Development, vol. 29, No 3, edición especial, Amsterdam, Elsevier Science.

Dirven, M. (2000): Empleo rural, grupos etarios y género, documento presentado en el Seminario "Ocupaciones rurales no-agrícolas" (Londrina, Brasil, 16 al 20 de octubre de 2000), Londrina, Paraná, Instituto Agronômico do Paraná (IAPAR).

(2001): Dairy clusters in Latin America in the context of globalization, International Food and Agribusiness Management Review, vol. 2, $\mathrm{N}^{\circ}$ 3-4, Amsterdam, Elsevier Science.

(2002): Las prácticas de herencia de tierras agrícolas: ¿una razón más para el éxodo de la juventud?, serie Desarrollo productivo, $\mathrm{N}^{\circ}$ 135, LC/L.1837-P, Santiago de Chile, CEPAL, diciembre. Publicación de las Naciones Unidas, $\mathrm{N}^{\mathrm{o}}$ de venta: S.02.II.G.143.

Elbers, C. y P. Lanjouw (2001): Intersectoral transfer, growth and inequity in rural Ecuador, World Development, vol. 29, $\mathrm{N}^{\circ} 3$, edición especial, Amsterdam, Elsevier Science.

Escobal, J. (2000): Costos de transacción en la agricultura peruana: una primera aproximación a su medición e impacto, Documento de trabajo, № 30, Lima, Grupo de Análisis para el Desarrollo (GRADE).

(2001): The determinants of nonfarm income diversification in rural Peru, World Development, vol. 29, No 3, edición especial, Amsterdam, Elsevier Science.

Ferreira, F. y P. Lanjouw (2001): Rural nonfarm activities and poverty in the Brazilian Northeast, World Development, vol. 29, No 3, edición especial, Amsterdam, Elsevier Science. 
Figueroa, A. (1986): Productividad y educación en la agricultura campesina de América Latina, Rio de Janeiro, Programa de Estudios Conjuntos de Integración Económica Latinoamericana (ECIEL).

Graziano da Silva, J. y M.E. del Grossi (2001): Rural nonfarm employment and incomes in Brazil: patterns and evolution, World Development, vol. 29, $\mathrm{N}^{\mathrm{o}} 3$, edición especial, Amsterdam, Elsevier Science.

Hataya, N. (1992): Urban-rural linkage of the labour market in the coffee growing zone in Colombia, The Developing Economies, vol. $30, \mathrm{~N}^{\circ} 1$, marzo, Tokio, Instituto de las Economías en Desarrollo.

Johnston, B. y P. Kilby (1975): Agriculture and Structural Transformation: Economic Strategies in Late Developing Countries, Londres, Oxford University Press.

Key, N., E. Sadoulet y A. de Janvry (2000): Transaction costs and agricultural household supply response, American Journal of Agricultural Economics, vol. 82, No 2, mayo, Massachusetts, Blackwell Publishers.

Klein, E. (1992): El empleo rural no agrícola en América Latina, Documento de trabajo, $N^{\circ} 364$, Santiago de Chile, Programa Regional del Empleo para América Latina y el Caribe (PREALC).

Lanjouw, P. (2001): Nonfarm employment and poverty in rural El Salvador, World Development, vol. 29, $\mathrm{N}^{\mathrm{o}} 3$, edición especial, Amsterdam, Elsevier Science.

Löfgren, H. y S. Robinson (1999): To Trade or Not to Trade: Nonseparable Farm Household Models in Partial and General Equilibrium, TMD Discussion Paper, N$^{\circ}$ 7, Washington, D.C., Instituto Internacional de Investigación sobre Políticas Alimentarias (IFPRI), Washington, D.C.

Morales, C. (2003): Lo rural y lo urbano: un ejercicio de simulación sobre estos conceptos, Santiago de Chile, Unidad de Desarrollo Agrícola, Comisión Económica para América Latina y el Caribe (CEPAL), inédito.

Persson, L. y V.A. Ceccato (2001): Dora-Dynamics of rural areas. National report: Sweden, Nordregio, Nordic Centre for Spatial Development, octubre (versión electrónica).

Primi, A. (2002): The Costs of Distance: Rural Poverty Through a Territorial Perspective, tesis de grado elaborada sobre la base del trabajo de práctica realizado en la División de Población de la CEPAL-Centro Latinoamericano y Caribeño de Demografía (CELADE) (septiembre-diciembre de 2002), Pavia, Italia, Universidad de Pavia.

Reardon, T., J. Berdegué y G. Escobar (2001): Rural nonfarm employment and incomes in Latin America: Overview and policy implications, World Development, vol. 29, No 3 , edición especial, Amsterdam, Elsevier Science.

Renkow, M. (1998): Cities, Towns, and the Rural Non-farm Economy, documento presentado al taller del Instituto Internacional de Investigación sobre Políticas Alimentarias (IFPRI) "Strategies for stimulating growth of the rural non-farm economy in developing countries" (Washington, D.C., 17 al 20 de mayo de 1998).

Ruben, R. y M. Van den Berg (2001): Nonfarm employment and poverty alleviation of rural farm households in Honduras, World Development, vol. 29, $\mathrm{N}^{\mathrm{o}} 3$, edición especial, Amsterdam, Elsevier Science.

Schejtman, A. y J. Berdegué (2003): Desarrollo territorial rural, borrador presentado en el Taller del Inter Agency Group for Rural Development (Milán, 21 de marzo de 2003).

Schultz, T. (1964): Transforming Traditional Agriculture, New Haven, Yale University Press.

Wiggins, S. (2003): Can the Rural Non-farm Economy Beat Poverty in the Developing World? An Overview, documento presentado al Simposio "The rural non-farm economy in the developing world and transition economies: an answer to rural poverty?", 77a Conferencia anual de la Agricultural Economics Society (AES) (Seale-Hayne, Newton Abbott, Devon, 11 al 14 de abril de 2003).

Wiggins, S. y S. Proctor (2001): How special are rural areas? The economic implications of location for rural development Development Policy Review, vol. 19, $\mathrm{N}^{\circ} 4$, Londres, Instituto de Desarrollo de Ultramar.

Yúnez-Naude, A. y J.E. Taylor (2001): The determinants of nonfarm activities and incomes of rural households in Mexico, with emphasis on education, World Development, vol. 29, № 3 , edición especial, Amsterdam, Elsevier Science.

World Development (2001): Vol. 23, N 3, edición especial, Amsterdam, Elsevier Science. 